\title{
Fuzzy Inventory Model without Shortages Using Triangular Fuzzy Numbers and Signed Distance Method
}

\author{
A. M. P. Chandrasiri \\ Postgraduate Institute of Science, University of Peradeniya, Peradeniya, Sri Lanka.
}

\begin{abstract}
In this paper, we studied Economic Order Quantity (EOQ) inventory model without shortages. Our goal is to determine optimal order quantity and optimal total cost for the proposed model. We introduced triangular fuzzy numbers for ordering cost and carrying cost. Signed distance method is used for defuzzification. Sensitivity analysis is carried out through the results of the numerical example.
\end{abstract}

Keywords: Inventory model, triangular fuzzy numbers, signed distance method, defuzzification.

\section{Introduction}

The inventory may be defined as the physical stock of good, units or economic resources that are stored or reserved for smooth, efficient and effective functioning of business. Many companies have wide-ranging inventories, consisting of many items. Without inventories, customers would have to wait until their orders were filled from a source or were produced in a plant. Another reason for maintaining inventory is the price fluctuation of some raw materials; it would be profitable for a buyer to procure a sufficient quality of raw material at lower price and used it whenever needed. Just as inventory is the stock on any item or resource used in an organization, an inventory system or management is the set of policies and controls that monitor levels should be maintained, when stock should be replenished and how large orders should be; when items should be ordered (when to order) and how large the order should be (how much to order). A major objective in controlling inventory is to minimize total inventory cost.

Economic Order Quantity (EOQ) is one of the oldest and most commonly known technique. This model was first developed by Ford Harris and R. Wilson independently in 1915. The objective is to determine economic order quantity, $Q$ which minimizes the total cost of an inventory system, when demand occurs at a constant rate. The model is developed under following assumptions:

1. The system deals with single item.

2. The demand rate of $D$ units per time unit is known \& constant.

3. Quantity discounts are not available.

4. The item is produced in lots or purchases are made in orders. The ordering cost is constant.

5. Shortages are not allowed. Lead-time is known and is constant.

6. Replenishment rate is infinite.

7. Replenishment size, $Q$, is the decision variable.

8. $T$ is the cycle time.

9. The inventory holding cost, $C_{h}$, per unit per time unit is known and constant during the period under review.

With these assumptions, inventory usage has a saw tooth shape, as in Figure 1.1. Here, Q represents the amount that is ordered.

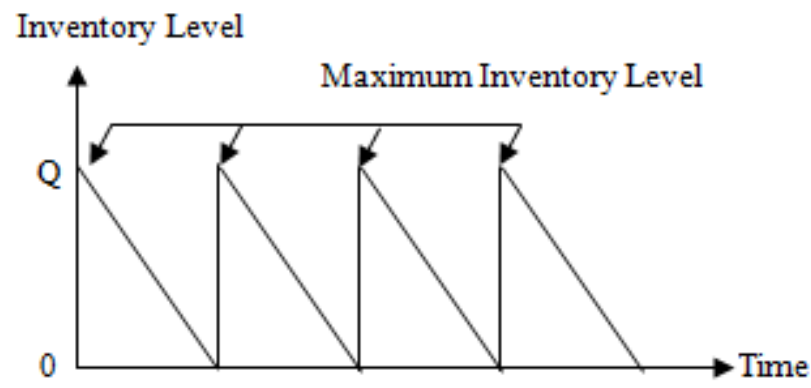

Figure 1.1: Inventory usage over time

Basically, model parameters are not defined exactly because various types of uncertainties and some irregularities in real inventory problems. So, they are classically modeled using probability theory. However, there are uncertainties that cannot be appropriately treated by standard probability concepts. Therefore, it becomes more convenient to deal such problems with fuzzy set theory rather than probability theory.

In this article, we developed an inventory model considering holding cost and ordering cost as triangular fuzzy numbers, and signed distance method is used for defuzzification. The total cost is expressed as a function of these two, and determine the reorder point that minimize the total cost.

\section{Literature Review}

The basic well known square root formula for EOQ model for constant demand was first given by Harris (1915). Wilson aroused interest in the EOQ model in academics and industries. Later, Hadley et al. analyzed many inventory systems.

In certain situation, uncertainties are due to fuzziness, primarily introduced by Zadeh in 1970. Jain worked on decision making in the presence of fuzzy variables. Kacpryzk et al. discussed some long term inventory policymaking through fuzzy-decision making models. Park (1987) examines the economic order quantity model (EOQ) from 


\section{International Journal of Science and Research (IJSR) \\ ISSN (Online): 2319-7064}

Index Copernicus Value (2013): 6.14 | Impact Factor (2015): 6.391

the fuzzy set theoretic approach. Trapezoidal fuzzy numbers are used to model ordering cost and inventory holding cost. Lee et al. (1990) introduce the application of fuzzy set theory to lot-sizing in material requirements planning.

For defuzzification, the study shows that signed distance method is better than centroid by Yao and Lee.

\section{Basic Definitions and Preliminaries}

Definition 3.1: Let $\bar{A}$ be a fuzzy set on $\mathbb{R}=(-\infty, \infty)$. It is called a fuzzy point if its membership function is

$$
\mu_{\bar{A}}(x)=\left\{\begin{array}{l}
1 ; x=a \\
0 ; x \neq a
\end{array}\right.
$$

Definition 3.2: Let $[a, b: \alpha]$ be a fuzzy set on $\mathbb{R}$. It is called a level $\alpha$ fuzzy interval, $0 \leq \alpha \leq 1, a<b$, if its membership function is

$$
\mu_{[a, b ; \alpha]}(x)=\left\{\begin{array}{l}
\alpha, \text { if } a \leq x \leq b \\
0, \text { if } \quad x \neq a
\end{array}\right.
$$

If $a=b$, we call $[a, b ; \alpha]$ a level $\alpha$ fuzzy point at a.

Definition 3.3: Among the various shapes of fuzzy number, triangular fuzzy number (TFN) is the most popular one. It is a fuzzy number represented with three points as follows:

$$
\bar{A}=(a, b, c)
$$

This representation is interpreted as membership functions.

$$
\mu_{\bar{A}}(x)=\left\{\begin{array}{cc}
0 & x<a \\
\frac{x-a}{b-a} ; & a \leq x \leq b \\
\frac{c-x}{c-b} ; & b \leq x \leq c \\
0 & x<c
\end{array}\right.
$$

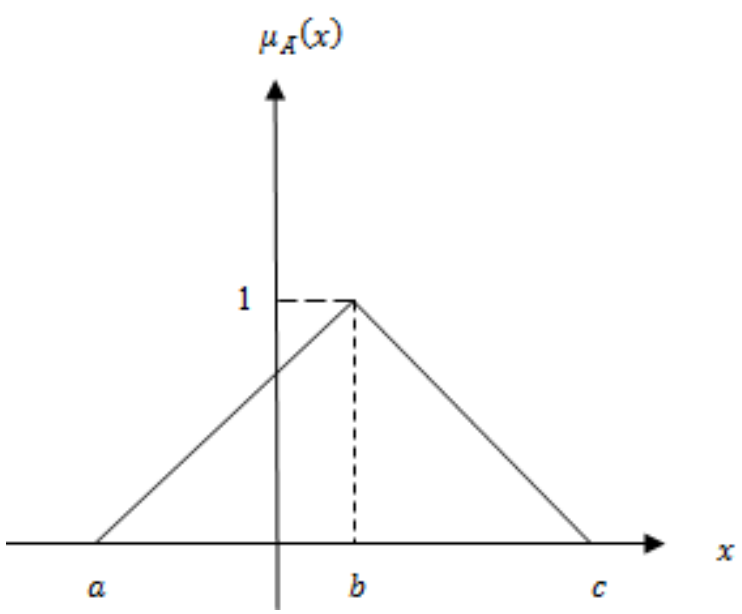

Figure 3.1: Triangular Fuzzy numbers $A=(a, b, c)$

Definition 3.4: Operations of Triangular Fuzzy Numbers Some important properties of operations on triangular fuzzy numbers are summarized as follows. Suppose $\bar{A}=$ $\left(a_{1}, b_{1}, c_{1}\right)$ and $\bar{B}=\left(a_{2}, b_{2}, c_{2}\right)$ are two triangular fuzzy numbers, then arithmetical operations are defined as follows:

$$
\begin{aligned}
A \oplus B & =\left(a_{1}, b_{1}, c_{1}\right) \oplus\left(a_{2}, b_{2}, c_{2}\right) \\
& =\left(a_{1}+b_{1}, a_{2}+b_{2}, a_{3}+b_{3}\right)
\end{aligned}
$$

2. The symmetric image of $\mathrm{A}$ is:

$$
-A=-\left(a_{1}, b_{1}, c_{1}\right)=\left(c_{1}, b_{1}, a_{1}\right)
$$

3. The results from multiplication or division are not triangular fuzzy numbers.

Definition 3.5: The $\alpha$-level set of the triangular number $\bar{A}=(a, b, c)$ is:

$$
A(\alpha)=\left\{x \mid \mu_{A}^{-}(x) \geq \alpha\right\}=\left[A_{L}(\alpha), A_{R}(\alpha)\right]
$$

where

$$
\begin{aligned}
& A_{L}(\alpha)=a+(b-a) \alpha \\
& A_{R}(\alpha)=c-(c-b) \alpha, \alpha \in[0,1]
\end{aligned}
$$

We represent

$$
\begin{aligned}
\bar{A} & =(a, b, c) \\
& =\cup\left[A_{L}(\alpha), A_{R}(\alpha)\right] ; 0 \leq \alpha \leq 1 .
\end{aligned}
$$

\section{Definition 3.6: The Signed Distance Method}

Defuzzification of $\bar{A}$ can be found by signed distance method. If $\bar{A}$ is a triangular fuzzy number then sign distance from $\bar{A}$ to 0 is defined as:

$$
d(\bar{A}, 0)=\frac{1}{2} \int_{0}^{1}\left(\left[A_{L}(\alpha), A_{R}(\alpha)\right], 0\right) d \alpha
$$

where

$$
\begin{aligned}
& A_{\alpha}=\left[A_{L}(\alpha), A_{R}(\alpha)\right] \\
& A_{\alpha}=[a+(b-a) \alpha, b-(b-c) \alpha], \alpha \in[0,1] \\
& \text { is } \alpha-\text { cut of fuzzy set } \bar{A} \text {, which is a close interval. }
\end{aligned}
$$

\section{Notations and Assumptions}

\subsection{Notations}

Let us now define the following parameters:

$Q^{*}=$ optimal order quantity (i.e., the EOQ)

$Q=$ order quantity per cycle

$D=$ annual demand, in units, for the inventory item

$C_{0}=$ ordering cost per order

$C_{h}=$ carrying or holding cost per unit per year

$T=$ Length of cycle/plan

$T C=$ total cost for the period $[0, \mathrm{~T}]$

$\widetilde{T C}=$ fuzzy total cost for the period $[0, \mathrm{~T}]$

\subsection{Assumptions}

In this model, the following assumptions are considered:

1. Total demand is considered as constant.

2. Time of the plan is constant.

3. Shortage is not allowed.

1. The addition of $\bar{A}$ and $\bar{B}$ is: 


\section{International Journal of Science and Research (IJSR) \\ ISSN (Online): 2319-7064}

Index Copernicus Value (2013): 6.14 | Impact Factor (2015): 6.391

\section{Model Formulation}

\subsection{Finding the Economic Order Quantity in Crisp Sense}

Total ordering cost $=\left(\frac{D}{Q}\right) \times C_{0}$

Total carrying cost $=\left(\frac{Q}{2}\right) \times C_{h}$

Total cost $=$ Total ordering cost + Total carrying cost

$$
T C=\left(\frac{D}{Q}\right) \times C_{0}+\left(\frac{Q}{2}\right) \times C_{h}=C(Q)(\text { say })
$$

The presence of $Q$ in the denominator of the first term makes equation (5.1) a nonlinear equation with respect to $Q$. The optimum $Q^{*}$ can be obtained by equating the first order derivative at $T C$ to zero and solving the resulting equations.

$$
\text { Optimal order quantity }=Q^{*}=\sqrt{\frac{2 D C_{0}}{C_{h}}}
$$

\subsection{Finding the Economic Order Quantity in Fuzzy Sense}

We consider the model in fuzzy environment, since the ordering cost and holding cost are in fuzzy nature; we represent them by triangular fuzzy numbers.

Let

$\widetilde{C}_{h}:$ Fuzzy carrying cost per unit quantity per year

$\widetilde{C}_{o}$ : Fuzzy ordering cost per order

The total demand and time of plan are considered as constants. The fuzzy total cost is given by

$$
\widetilde{T C}=\left(\frac{D}{Q}\right) \times \widetilde{C} o+\left(\frac{Q}{2}\right) \times \widetilde{C}_{h}
$$

where wavy bar $\left(^{\sim}\right)$ indicates fuzzification of parameters.

In real world situations, it is difficult to decide the ordering cost and carrying cost for long period due to some uncertainties. Therefore, we define ordering cost $\left[C_{0}-\right.$ $\Delta 1, C O+\Delta 2$ where $0<\Delta 1<C 0$ and $\Delta 1, \Delta 2>0$ such as $\Delta 1, \Delta 2$ are chosen appropriately. Also, suppose carrying cost lies in the interval $\left[C_{h}-\Delta_{3}, C_{h}+\Delta_{4}\right]$. So, we can find a fuzzy number to represent the vagueness in ordering cost and carrying cost as:

$\widetilde{C}_{o}=\left(C_{o}-\Delta_{1}, C_{o}, C_{o}+\Delta_{2}\right)$ where $0<\Delta_{1}<C_{o}, \Delta_{1}, \Delta_{2}>0$

$\widetilde{C}_{h}=\left(C_{h}-\Delta_{3}, C_{h}, C_{h}+\Delta_{4}\right)$ where $0<\Delta_{3}<C_{h}, \Delta_{3}, \Delta_{4}>0$

Now,

$\widetilde{T C}=$

$=\left\lfloor\left(\frac{D}{Q}\right) \times\left(C_{o}-\Delta_{1}, C_{o}, C_{o}+\Delta_{2}\right)\right\rfloor \oplus\left\lfloor\left(\frac{Q}{2}\right) \times\left(C_{h}-\Delta_{3}, C_{h}, C_{h}+\Delta_{4}\right)\right\rfloor$

$=\left(F_{1}, F_{2}, F_{3}\right)$ (say)

where

$$
\begin{aligned}
F_{1} & =\left[\left(\frac{D}{Q}\right) \times\left(C_{0}-\Delta_{1}\right)\right] \oplus\left[\left(\frac{Q}{2}\right) \times\left(C_{h}-\Delta_{3}\right)\right] \\
& =C(Q)-\left(\left(\frac{D}{Q}\right) \Delta_{1}+\left(\frac{Q}{2}\right) \Delta_{3}\right) \\
F_{2} & =C(Q) \\
F_{3} & =\left[\left(\frac{D}{Q}\right) \times\left(C_{0}+\Delta_{2}\right)\right] \oplus\left[\left(\frac{Q}{2}\right) \times\left(C_{h}+\Delta_{4}\right)\right] \\
& =C(Q)+\left(\left(\frac{D}{Q}\right) \Delta_{2}+\left(\frac{Q}{2}\right) \Delta_{4}\right)
\end{aligned}
$$

Defuzzification of fuzzy number $\widetilde{T C}$ by using signed distance method is given as:

$d(\tilde{T} C, 0)=\frac{1}{2} \int_{0}^{1}\left(\left[A_{L}(\alpha), A_{R}(\alpha)\right], 0\right) d \alpha$

where

$A_{L}(\alpha)=F_{1}+\left(F_{2}-F_{1}\right) \alpha$ and

$A_{R}(\alpha)=F_{3}-\left(F_{3}-F_{2}\right) \alpha$

So,

$$
\begin{aligned}
d(\widetilde{T C}, 0) & =C(Q)+\frac{1}{4}\left[\left(\frac{D}{Q}\right)\left(\Delta_{2}-\Delta_{1}\right)+\left(\frac{Q}{2}\right)\left(\Delta_{4}-\Delta_{3}\right)\right] \\
& =C_{d}(Q) \text { (say) }
\end{aligned}
$$

Differentiate the equation (5.2) w. r. t. $Q$ and equating it to zero, $C_{d}(Q)$ is minimum when $C_{d}^{\prime}(Q)=0$ where $C_{d}^{\prime \prime}(Q)>$ 0 .

Hence,

$$
Q^{*}=\sqrt{\frac{2 D\left(4 C_{o}+\left(\Delta_{2}-\Delta_{1}\right)\right)}{\left(4 C_{h}+\left(\Delta_{4}-\Delta_{3}\right)\right)}}
$$

Also, at $Q=Q^{*}$ we have $C_{d}^{\prime \prime}\left(Q^{*}\right)>0$.

This shows that $C(Q)$ is minimum at $Q=Q^{*}$.

\section{Algorithm for Finding Fuzzy Total Cost and Fuzzy Optimal Order Quantity:}

Step I: Calculate total cost (TC) for the crisp model sense for the given crisp value.

Step II: Determine fuzzy total cost $(\widetilde{T C})$ using fuzzy arithmetic operations on fuzzy carrying and ordering cost, taken as fuzzy triangular numbers.

Step III: Use signed distance method for defuzzification of $(\widetilde{T C})$. Then, find fuzzy optimal order quantity $Q^{*}$, using first and second derivative test.

\section{Numerical Example}

To illustrate the developed model (both in crisp \& fuzzy sense), we have taken an example.

In crisp sense

Let,

$D=600$ units per units

$C_{h}=$ Rs. 10 per unit $(T=1)$

$C_{o}=$ Rs. 100 per order

Then, optimal order quantity $Q^{*}=109.54$ units and the minimum cost per year $T C_{\min }=T C^{*}=$ Rs. 5532.00.

\section{Volume 5 Issue 7, July 2016}




\section{International Journal of Science and Research (IJSR) \\ ISSN (Online): 2319-7064}

Index Copernicus Value (2013): 6.14 | Impact Factor (2015): 6.391

\section{In fuzzy sense}

Let,

$D=600$ units per units

$C_{h}=$ Rs. 10 per unit $(T=1)$

$C_{o}=$ Rs. 100 per order

$\Delta_{1}=2, \Delta_{2}=5, \Delta_{3}=3, \Delta_{4}=1$

Then, we get $Q^{*}=111.40$ units and the minimum cost per year $T C_{\min }=T C^{*}=$ Rs. 5600.17 .

Table 6.1: Sensitivity Analysis

\begin{tabular}{|c|c|c|c|c|c|}
\hline \multirow{2}{*}{ No } & \multirow{2}{*}{ Demand } & \multicolumn{2}{|c|}{$\Delta=(2,5,3,1)$} & \multicolumn{2}{c|}{$\Delta=(2,4,2,1)$} \\
\cline { 3 - 6 } & & $Q^{*}$ & $T C^{*}(\mathrm{Rs})$. & $Q^{*}$ & $T C^{*}(\mathrm{Rs})$. \\
\hline 1 & 600 & 111.40 & 5600.17 & 110.10 & 5548.70 \\
\hline 2 & 625 & 113.70 & 5715.65 & 112.38 & 5663.12 \\
\hline 3 & 650 & 115.95 & 5828.85 & 114.60 & 5775.27 \\
\hline 4 & 675 & 118.16 & 5939.88 & 116.78 & 5885.28 \\
\hline 5 & 700 & 120.33 & 6048.88 & 118.93 & 5993.28 \\
\hline
\end{tabular}

\section{Conclusion}

In this paper, we have worked on Economic Order Quantity (EOQ) inventory model without shortages. Here, we have used signed distance method for defuzzification the total cost. We pointed out that for EOQ model, holding cost and ordering cost can be expressed as triangular fuzzy numbers. Finally, we conclude that the Economic Order Quantity obtained by signed distance method is closer to crisp Economic Order Quantity and total cost obtained by signed distance method is more than crisp total cost. Also, Economic Order Quantity is more sensitive towards the demand and total cost increases as the demand increases.

\section{References}

[1] L. A. Zadeh, "Fuzzy Sets," Information Control, pp. 338-353, 1965.

[2] L. A. Zadeh, R. E. Bellman, "Decision Making in Fuzzy Environment", Management Science, pp. 140$164,1970$.

[3] H. J. Zimmerman, "Using Fuzzy Sets in Operation Research," European Journal of Operation Research, pp. 201-206, 1983.

[4] P. K. De, A. Rawat, "A Fuzzy Inventory Model Without Shortages using Triangular Fuzzy Number," Fuzzy Information \& Engineering, pp. 59-68, 2011.

[5] J. S. Yao, J. Chiang, "Inventory without back order with fuzzy total cost and fuzzy storing cost defuzzified by centroid and signed distance," European Journal of Operation Research, pp. 401-409, 2003.

[6] J. K. Syed, L. A. Aziz, "Fuzzy Inventory Model without Shortages Using Signed Distanced Method," Applied Mathematics and Information Sciences, pp. 203-209, 2007.

[7] Y. Karwowski, G. W. Evans, "Fuzzy Concepts in Production Management Research," International Journal of Production Research, pp. 129-147, 1986.

[8] A. M. P. Chandrasiri, "Fuzzy Inventory Model without Shortages using Signed distance method," International Journal of Science and Research, pp. 187-190, 2016.

[9] G. Urgeletti, "Inventory Control Models and Problems," European Journal of Operation Research, pp. 1-12, 1983.
[10] D. Dubois, H. Prade, "Fuzzy Sets and Systems: Theory and Applications", Newyork, 1980.

\section{Author Profile}

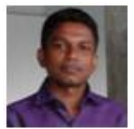

A. M. P. Chandrasiri received the B.Sc. degree in Mathematics (special) from University of Peradeniya, Sri Lanka in 2013. In 2014, he worked at University of Peradeniya. From 2014 -present, he is working in Uva Wellassa University of Sri Lanka. Now, he is reading M. Sc degree in industrial Mathematics at Postgraduate Institute of Science, University of Peradeniya, Sri Lanka. His research interest in operation research and discrete mathematics. 